\title{
Pedagogias culturais em tempos de pandemia: educações nos muros de Londrina
}

\author{
Cultural pedagogies in pandemic times: education \\ on the walls in Londrina
}

\section{Pedagogías culturales en tiempos pandémicos: educación en las paredes de Londrina}

\author{
Alexandre Luiz Polizel' \\ https://orcid.org/0000-000 I-6397-306X \\ Bruna Adriane Fary ${ }^{2}$ \\ https://orcid.org/0000-0002-2382-6572 \\ Cristiane Beatriz Dal Bosco Rezzadori ${ }^{3}$ \\ https://orcid.org/0000-0003-0227-759|
}

\begin{abstract}
Resumo: $O$ presente trabalho tem por objetivo traçar considerações acerca das pedagogias culturais nos muros do município de Londrina-PR em tempos de pandemia. Para tal lançamos mãos de um olhar hermenêutico ancorado nos Estudos Culturais das Ciências e das Educações, de base epistêmica em Michel Foucault e Bruno Latour. A interpretativa é lançada a partir de dois pixo nas paredes da região central do município de LondrinaParaná no início da pandemia de COVID-19, sendo o registro foto-capitado em abril de 2020. A partir da leitura de ambos é possível a taxonomização de duas pedagogias culturais operantes que orientam este manuscrito: a) O reiterar de técnicas de prevenção para com as infecções virais; e b) Uma crítica sócio-cultural das possibilidades éticas do cuidado de si.
\end{abstract}

Palavras-chave: Pedagogias culturais. Estudos culturais. Cuidado de si.

\footnotetext{
' Doutorando no Programa de Pós-graduação em Ensino de Ciências e Educação Matemática da Universidade Estadual de Londrina. Professor no Departamento de Educação da Universidade Estadual de Londrina. E-mail: Alexandre_polizel@hotmail.com

${ }^{2}$ Doutora em Ensino de Ciências e Educação Matemática pela Universidade Estadual de Londrina. E-mail: fary.bruna@gmail.com

${ }^{3}$ Doutora em Ensino de Ciências e Educação Matemática pela Universidade Estadual de Londrina. Professora no Departamento de Química da Universidade Tecnológica Federal do Paraná, Câmpus Londrina. E-mail: crezzadori@utfpr.edu.br
}

Olhar de professor, Ponta Grossa, v. 24, p. I-7, e-16067.060, 2021.

Disponível em <https://revistas2.uepg.br/index.php/olhardeprofessor> 
Abstract: This paper aims to outline considerations about cultural pedagogies on the walls of the city of Londrina-PR in times of pandemic. To this end, we use a hermeneutic look anchored in the Cultural Studies of Sciences and Education, based on epistemics in Michel Foucault and Bruno Latour. The interpretative is launched from two graffiti written on the walls of the central region of the city of Londrina-Paraná at the beginning of the COVID-19 pandemic, with the photo-capitized record in April 2020. From the reading of both it is possible to taxonomization of two cultural pedagogies that guide this manuscript: a) The reiteration of prevention techniques for viral infections; and b) A socio-cultural critique of the ethical possibilities of self-care.

Keywords: Cultural pedagogy. Cultural studies. Take care of yourself.

Resumen: Este artículo tiene como objetivo esbozar consideraciones sobre pedagogías culturales en los muros de la ciudad de Londrina-PR en tiempos de pandemia. Para este fin, utilizamos una mirada hermenéutica anclada en los Estudios Culturales de Ciencias y Educación, basada en la epistémica Michel Foucault y Bruno Latour. El interpretativo se lanzó desde dos graffitis escritos en las paredes de la región central de la ciudad de LondrinaParaná al comienzo de la pandemia de COVID-19, con el registro fototitulado en abril de 2020. De la lectura de ambos es posible taxonomización de dos pedagogías culturales de trabajo que guían este manuscrito: a) La reiteración de las técnicas de prevención de infecciones virales; yb) Una crítica sociocultural de las posibilidades éticas del autocuidado.

Palabras clave: Pedagogía cultural. Estudios culturales. Cuídate.

\section{Notas introdutórias}

A vida em tempos de crise é tema que conhecemos de longa data, segundo Boaventura de Sousa Santos (2020). Sendo a doença COVID- 19 uma crise, existem articulações para traçar resolutivas e trazer à tona reflexões, dentre elas, questões pedagógicas. Múltiplos olhares são traçados às educações em época de pandemia: as tentativas de retorno à normalidade educativa, o infiltrar de medidas neoliberais que buscam tornar as educações em materiais digitais e pensar como o próprio vírus nos ensina algo (SANTOS, 2020).

É no caminho do refletir educações e suas pedagogias em tempos pandêmicos que nos colocamos a indagar as produções pedagógicas anônimas. As pedagogias que falam sem pretensão de ter um autor que explica, pontua e salva. É considerar as pedagogias como modos de ensinar, aprender e constituir conhecimento que vazam e mantem-se conectadas com os espaços escolares - haja visto que os muros da escola são porosos -, mas não apenas dentro destes. São pedagogias produzidas nos encontros com humanos e não humanos, com a cultura e seus artefatos culturais, com as reflexões e os afetos (ANDRADE; COSTA, 20I5; LATOUR, 20I3). São nos encontros contingenciais, históricos e simbólicos que tais pedagogias se dão: pedagogias culturais.

É em um destes encontros pedagógicos que o presente trabalho emerge, do concílio com dois pixos $^{4}$ que marcam as paredes da região central do município de Londrina, Paraná e que produzem registros fotográficos no mês de abril de 2020. Pixos que explanam sobre o ar do tempo, expressam

\footnotetext{
${ }^{4}$ Compreendemos o uso da palavra picho enquanto derivativo dos sentidos dos usos de derivados de petróleo para tingir, escrever, tapar ou marcar algo. Entretanto, preferimos operacionalizar neste texto o pixo enquanto escape da linguagem coloquial, na possibilidade da reivindicação de sentidos e de seus usos populares, políticos e poéticos (TIBURI, 20II).
} 
linhas de produção de sentidos e saberes, efetuam uma pedagogia cultural com os corpos que se encontram com estes. Escrituras em paredes que não pretendem tornar-se uma verdade a ser seguida (FOUCAULT, 2016), mas que operacionalizam a "[...] experiência democrática da linguagem que se estende a todos os fenômenos" (TIBURI, 20I I, p. 7) e movimentam o pensamento acerca da pandemia. São pedagógicas, pois ensinam e constituem algo, promovem a reflexão acerca dos valores e dos conhecimentos para enfrentar a peste (NIETZSCHE, 20I2).

Tais pixos nos permitiram traçar, no presente ensaio, considerações acerca das pedagogias culturais nos muros do município de Londrina-PR em tempos de pandemia. Explanações que apresentamos neste manuscrito em um olhar ensaístico ${ }^{5}$, taxonomizando ${ }^{6}$, constituindo de duas técnicas pedagógicas que orientam este manuscrito: a) Técnicas de prevenção para com as infecções virais; e b) Críticas para um cuidado coletivo, em meio as possibilidades étnicas e técnicas.

\section{Técnicas para prevenção}

São nos trânsitos pelo centro do município de Londrina que o seguinte registro é realizado no muro de uma escola: Deus abençoe o álcool gel (Figura I).

Figura I: Deus abençoe o álcool gel, 2020.

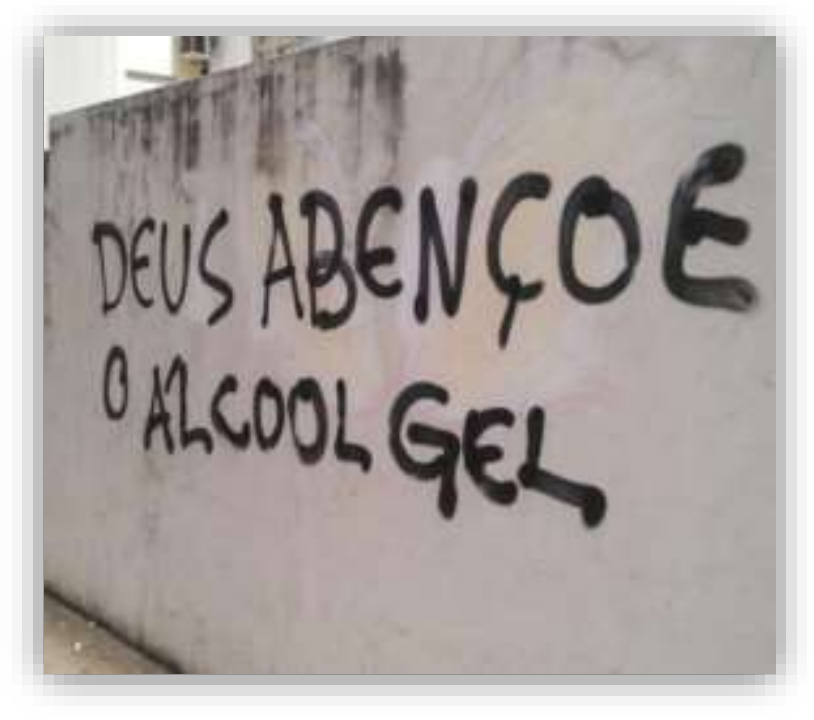

Fonte: Acervo pessoal, 2020.

\footnotetext{
${ }^{5}$ Reiteramos a utilização do ensaio e da ação da escrita enquanto procedimento metodológico, ao passo que a ensaística remete ao escrever e articular analises a partir de chaves conceituais (FOUCAULT, 20I6), agregação de atores-agencias (LATOUR, 20I3) e ao movimento do pensamento e constituição de saberes via processos de inscrição (NIETZSCHE, 20I2).

${ }^{6}$ Taxonomização é utilizada aqui enquanto recurso metafórico aos movimentos analíticos das ciências biológicas, operacionalizados por meio da descrição e nomeação de espécimes-fenômenos. Não utilizamos dessa torção conceitual para criar um sistema hierárquico, lançamos mãos para diagnosticar um sistema de funcionamento pedagógico por meio de duas tecnologias: tecnologia da prevenção e tecnologia crítica do cuidado de si.
} 
Tal inscrito - conceito de Bruno Latour (2013) que considera o processo de inscrição enquanto processual de corporificação de saberes, modos de existência e de quadros de referência que situam os conhecimentos - poderia nos remeter a um agradecimento ao uso técnico de álcool gel para prevenção de enfermidades, o que inclui o vírus codificado enquanto COVID-19. Tal registro nos localiza em uma pedagogia cultural que coloca em discussão o discurso das ciências biológicas ${ }^{7}$, que tipificam o processo de desnaturação de proteínas de possíveis agentes etiológicos e suprime o potencial de infecção das mesmas.

É na referência às bases da biologia e dos usos de produtos desinfetantes que constituiria um nó de calibre da pedagogia que entoa os muros da cidade. É referência articulada que representa os testes laboratoriais via dispositivos experimentais, as propagandas de TV e suas divulgações/publicidades cientificas, as publicações nas redes sociais que buscam compartilhar informações com os amigos... É o registro derivativo do campo de saber biomédico, que situa os usos de técnicas científicas para prevenir infecções e inativar patógenos com o intuito do fazer viver, de uma biopolítica (FOUCAULT, 2016). Poderia ser um educador ao dizer, mas quem faz este papel na ausência das aulas presenciais é um pixo ${ }^{8}$.

O discurso que emerge a partir do campo de saber das biologias, remete também ao campo de saber religioso, dada a afirmativa: Deus abençoe o álcool gel. Bruno Latour (2013) categoriza a religiosidade enquanto um campo de saber, algo que produz conhecimento e sentidos, contudo o faz para além do olhar dogmático - que aprisiona e adoece o pensamento. Para o mesmo, a religião dá-se na linguagem do presente e na produção de unidade do momento, o que é dado por processos de traduções e busca de consonância de sentido. Em tal perspectiva a representação de "Deus abençoe" no pixo, remete ao uso do álcool gel pela coletividade, em unidade colaborativa para a prevenção do COVID-19; caso a coletividade não o faça uso, a unidade rui, pois não há benção9.

É na unidade do campo de saber religioso e na articulação de referenciais das biologias que a prevenção é possível, que a tecnologia da prevenção é efetuada e, que podem ser constituídos saberes e pedagogias em tempos de pandemia - pelo intermédio dos muros e suas marcas (TIBURI, 20II).

\footnotetext{
${ }^{7}$ Compreendemos discurso ancorado em Michel Foucault (2016), enquanto processo de produção de sentidos e sistemas simbólicos, que materializa regimes de verdades e produz as coisas - não apenas as representa.

${ }^{8}$ Fazemos o adendo de que o olhar ancorado nas pedagogias culturais não tem por intuito a substituição das pedagogias escolares (também culturais), apenas considera outras formas de aprender, ensinar e constituir saberes (ANDRADE; COSTA, 20I5).

${ }^{9}$ Fazemos uso da menção a benção por um olhar Latouriano (20l3), desconsiderando qualquer possibilidade de transcendência. Aqui afirmamos que a unidade é produzida na linguagem, no encontro, na coletividade e na imanência. A benção, valor afirmativo, é construída pelo uso da tecnologia de prevenção.
} 


\section{Críticas para um cuidado de si}

As representações da formulação do uso de álcool gel, ancorado em aspectos biológicos e religiosos, encontram outro escrito-inscrito que a coloca em questionamento. Um segundo pixo, em uma rua transversal o cruza epistemologicamente: Álcool gel < Água e sabão (Figura 2).

Figura 2: Álcool gel < Água e sabão, 2020

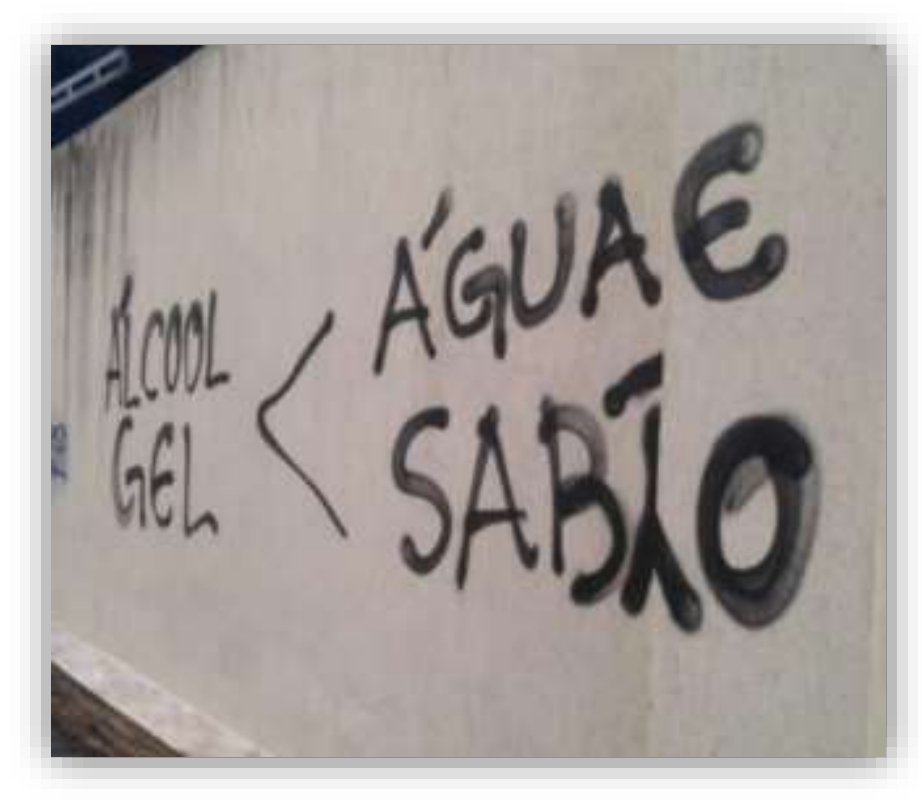

Fonte: Acervo pessoal, 2020

A afirmativa do pixo nos sinaliza críticas a tecnologia de prevenção pelo uso de álcool gel, sem desconsiderar a necessidade preventiva para com o agente infectante em tempos de pandemia. É a crítica que desloca os utensílios que podem ser acionados para o agir profilático. Michel Foucault (2016) aciona o uso da crítica enquanto uma diagnose que coloca as ambivalências e as condições de surgimento de discursividades no presente, apresenta ao olhar e a refletir para que possam ser (re)analisados. É o juízo que coloca também, para Friedrich Nietzsche (2012, p. I36) ○ “[...] instrumento do filósofo" a disponibilidade do pensamento e da "[...] educação". É a crítica que nos permite examinar o que as multiplicidades dizem (TIBURI, 20I I; SANTOS, 2020).

A utilização linguística do registro já instaura seu potencial crítico, utiliza-se do símbolo "<" para representar logicamente que os usos da água e sabão são melhores para a prevenção do que a utilização do álcool em gel. Não é utilizado como recurso linguístico um símbolo que coloca as duas técnicas de prevenção em igualdade, tão pouco que invalide o uso de um ou de outro. $O$ uso remete a uma demarcação qualitativa do potencial da água e sabão. 
Pedagogias culturais em tempos de pandemia: educações nos muros de Londrina

Várias podem ser as explanações e movimentar do pensamento, as filosofias e pedagogias a serem pensadas a partir deste pixo (TIBURI, 20I I): i) a película que alguns álcoois géis deixam na mão, que funcionam enquanto um substrato para o desenvolvimento de outros micro-organismos; ii) a crítica ao sistema capitalizado do álcool gel, que confere poder pleno de prevenção as indústrias farmacêuticas e instituições que agenciam os biopoderes vigentes; iii) a amplitude que o lavar as mãos com água e sabão remete, haja visto que seu funcionamento bioquímico não age apenas por desnaturação de proteínas para lise viral, ele age também na lise via membrana plasmática - o que serve também para a prevenção de vírus que possuem membrana externa-envelope viral); iv) a reflexão acerca dos usos de artefatos e técnicas que já se possui acesso, água e sabão, ao invés de incentivar um novo nicho de consumo; e v) o pensar as técnicas da prevenção democratizada, a todos, associada ao cuidado de si cotidiano, ao passo que o acesso a água e sabão é mais amplo que o acesso ao álcool em gel.

É neste conectivo em que se produz uma pedagogia que remete a uma técnica de prevenção sem perder de vista o pensar de múltiplos usos e técnicas outras, é este que remete a um expandir as noções de acesso da mesma, considerá-las modos de vida (FOUCAULT, 20I6; LATOUR, 20I3). A preocupação com o corpo e com o Outro é materializada, no segundo pixo, ao pensar a possibilidade coletiva de cuidado de modo ético, da construção de valores-entendimentos-usos e de seus acessos. É a coletividade que o segundo pixo nos remete e afirma: Ácool gel < Água e sabão. É em um coletivo que remete aos sujeitos enquanto similitude das singularidades e não por acesso utilitário a bens de consumo. É a pedagogia voltada a uma grande saúde (NIETZSCHE, 2012; SANTOS, 2020).

\section{Considerações finais}

Ao pensar educações em tempos de pandemia, esbarramo-nos com pedagogias culturais que marcam os muros de Londrina-PR por meio de pixos. Evidenciamos, a partir de dois pixos que marcam as paredes da região central do município, duas técnicas que articuladas compõem pedagogias culturais para enfrentamento do COVIDI 9: i) Técnicas para a prevenção para com as infecções virais, lançando mão de álcool gel associado ao estabelecimento de uma comunidade-unidade que faz uso das técnicas de prevenção; e ii) Reflexões que guiam a uma crítica para o cuidado coletivo, pensando nas possibilidades éticas e técnicas de uso de acesso aos múltiplos indivíduos que constituem a sociedade - o uso de água e sabão.

\section{Referências}

ANDRADE, P. D.; COSTA, M. V. Usos e possibilidades do conceito de pedagogias culturais nas pesquisas em estudos culturais em educação. Textura, 17, n. 34, p. 48-63, Canoas-RS, maio/ago. 2015.

Olhar de professor, Ponta Grossa, v. 24, p. I-7, e-16067.060, 2021.

Disponível em <https://revistas2.uepg.br/index.php/olhardeprofessor> 
FOUCAULT, M. Microfísica do poder. 4. ed. Rio de Janeiro: Paz \& Terra, 2016.

LATOUR, B. Investigación sobre los modos de existência. Ciudad Autónoma de Buenos Aires: Paidós, 2013.

NIETZSCHE, F. Além do bem e do mal: prelúdio de uma filosofia do futuro. Petrópolis: Vozes, 2012.

SANTOS, B. S. A cruel pedagogia do vírus. Coimbra: Edições Almedina, 2020.

TIBURI, M. Filosofia pop: poder e biopoder. São Paulo: Bregantini, 20I I.

Recebido em: 15 de junho de 2020.

Versão corrigida recebida em: 05 de novembro de 2020.

Aceito em: 05 de novembro de 2020.

Publicado online em: II de junho de 202I. 